scale vaccination of domestic animals can prevent animal disease and renal excretion of leptospires. Human vaccines have been used overseas in high risk groups with varied success, but vaccines produced in rabbit serum may cause serious side effects. No human vaccine is available in the United Kingdom. The counsel of perfection is to avoid all contaminated waters, but simple precautions may reduce even further the small risk. Warning or safety cards containing the advice outlined in the box can be issued to people. There is no value in routine antibody screening for employment purposes. Should an individual become ill the safety card should be shown to his or her doctor, who can obtain advice from the microbiologist at the local hospital. In England and Wales public health laboratories offer diagnostic serological testing, and the Leptospira Reference Laboratory accepts serum samples for confirmation or from seriously ill patients in whom the diagnosis is in doubt.
Undoubtedly leptospirosis is underdiagnosed owing to its non-specific presentation, but probably few severe or fatal cases are missed. $L$ hardjo and $L$ icterohaemorrhagiae are the most common infecting serovars in the United Kingdom. Despite the recent reported increase in the rat population the increase in cases due to $L$ icterohaemorrhagiae in 1988 was not maintained in $1989 .{ }^{4}$

IAN R FERGUSON

Director,

Public Health Laboratory,

County Hospital,

Hereford HR1 2ER

1 International Union of Microbiological Societies Subcommittee on the Taxonomy of Leptospira. Revised list of Leptospira serovars. Gronogen: University Press, 1988.

Turner LH. Leptospirosis. BMF 1969;i:231-5.

3 Watt G, Padre LP, Tuazon L, et al. Placebo-controlled trial of intravenous penicillin for severe and late leptospirosis. Lancet 1988;i:433-3.

4 Golding C. Rats - the new plague. London: Weidenfield and Nicholson, 1990.

\title{
Management of injuries due to chemical weapons
}

\section{Most patients exposed to mustard gas recover completely}

The use (though not the possession) of chemical warfare agents is banned by international treaty. Nevertheless, Iraq has used these weapons recently and is likely to do so again if conflict breaks out in the Gulf. They were used most recently during the Iraq-Iran war, when Iraq used mustard gas (and possibly the nerve agent Tabun) against troops and Kurdish civilians. Some of these casualties were treated in London, so we have some recent experience of managing the victims of chemical weapons. What are the predominant agents? What injuries do they cause? and What is the outlook for their victims?

Since chemical weapons were first used on a large scale during the first world war a wide range has been developed, but only a small number of these are likely to be used by an aggressor. Because of their high volatility compounds such as hydrogen cyanide, phosgene, and chlorine are unlikely to be used. Mustard gas and nerve agents are likely to present the major risk.

Mustard gas (sulphur mustard) is a liquid which gives off a dangerous, visicant vapour. Unprotected individuals exposed to either the vapour or the liquid develop blistering of the skin, eye damage, and, if they inhale the vapour, damage to the upper respiratory tract. An asymptomatic latent period of up to six or so hours is classically described before features develop, an early reddening of the skin then progressing to blisters, which may be large and pendulous but tend not to be painful. Eye damage is commonly restricted to the anterior part of the eye, though severe pain, tearing, and corneal damage may take up to six weeks to resolve. Absorption of the compound may cause depression of the bone marrow, reaching a nadir some two weeks after exposure. Death, which in the first world war occurred in about $2 \%$ of mustard gas victims, results from burns, respiratory tract damage, and bone marrow depression.

Treatment of mustard gas exposure is according to symptoms. The skin lesions should be treated like thermal burns, large blisters being drained under aseptic conditions. The blister fluid in such cases is often claimed to be dangerous in itself, threatening secondary blistering of attendants: this is untrue. Damage to the eyes should be treated by daily irrigation; mydriatics to ease the eye pain produced by spasm of the ciliary muscle and to prevent the iris sticking to the lens; antibiotic drops; and, if necessary, systemic analgesics. The use of sterile petroleum jelly to prevent the lid margins sticking together is also recommended. Dark glasses and reassurance are very important as the eye lesions produce severe photophobia and fear. The value of local anaesthetics and steroid drops is more controversial, and they should not be used without expert advice.

Damage to the upper respiratory tract should be treated according to symptoms, and antibiotic cover provided to prevent infection. The most severely affected patients may need assisted ventilation and oxygen enriched air.

Most patients exposed to mustard gas recover completely, and only a small proportion will have long term eye or lung damage. Though sulphur mustard is a known human carcinogen, the risk associated with a single exposure is remote.

Nerve agents pose a more serious threat, particularly to the unprotected. They are organophosphorus compounds which inhibit the enzyme acetylcholinesterase and therefore interfere widely with the functioning of the nervous system. They are closely related to organophosphorus pesticides, and treatment of casualties exposed to these agents is broadly similar to the treatment of those poisoned with organophosphorus pesticides. Nerve agents may be encountered on the battlefield in both the vapour and liquid phases.

The early symptoms of nerve gas poisoning include miosis, rhinorrhoea, hypersalivation, and headache. In the most severely poisoned these may progress to impairment of neuromuscular transmission leading to respiratory failure. Vomiting, convulsions, and damage to the central respiratory drive may also occur, causing death from respiratory failure. Treatment includes the use of atropine, oximes (which reactivate the inhibited cholinesterase), and the anticonvulsant diazepam. The efficacy of treatment may be greatly enhanced by giving pyridostigmine before exposure to a nerve agent. Pyridostigmine binds reversibly to some of the cholinesterase and prevents that proportion being attacked by nerve agent. During the recovery period after poisoning with nerve agents binding of cholinesterase to pyridostigmine is reversed and uninhibited enzyme reappears from this protected store. Members of the United Kingdom armed forces have pyridos- 
tigmine tablets to take before exposure and autoinjection devices to allow the rapid administration of atropine, oxime, and diazepam after exposure.

Should members of the armed forces fall victim to exposure from chemical weapons immediate treatment will be provided by the armed forces medical services. Before evacuation to the United Kingdom all casualties will have been decontaminated and stabilised, so that doctors in the United Kingdom are likely to be concerned mainly with the late effects of exposure. Burns surgeons, dermatologists, respiratory physicians, and ophthalmologists are likely to be most heavily concerned with victims of mustard gas, whereas clinical toxicologists, general physicians, neurologists, and anaesthetists are likely to be concerned with the victims of nerve agents, whose treatment may be prolonged.

Fuller information on management is available, ${ }^{1-3}$ and up to date advice will be available to doctors from both the Poisons Information Services and the Department of Health, which will also be monitoring any cases.

Honorary Consultant Occupational Toxicologist

V S G MURRAY

Director,

G N VOLANS

National Poisons Information Service,

Guy's Hospital

London SE1 9RT

1 Beswick FW, Maynard RL. Poisoning in conflict. In: Weatherall DJ, Ledingham JGG, Warrell DA eds. Oxford textbook of medicine. Vol 1. 2nd ed. Oxford: Oxford University Press, 1987:6.59-6.65. Ministry of Defence. Medical manual of defence against chemical agents. London: HMSO, 1987. (JSP312.)

Goodman LS, Gilman A, eds. Goodman and Gilman's the pharmacological basis of therapeutics. London: Ballière Tindall, 1987.

\section{The NHS prepares for war}

\section{There should be lessons for peacetime}

As the journal goes to press the possibility of war in the Gulf comes ever closer. The Department of Health has drawn up plans for treating casualties in the NHS that have been widely leaked to the press, but nobody knows exactly what load will be placed on the service.

Britain has 30000 troops in the Gulf, and the plans assume that the NHS will be dealing almost entirely with British casualties. From the moment that war seems inevitable all regional health authorities will be put on alert. Arrangements have been made to fly casualties to 22 different airports around the country. The most seriously injured casualties will be kept in the Gulf for up to four days, but those able to withstand a delay of more than 12 hours in receiving treatment will be flown back to Britain. Depending on developments in the war, NHS hospitals may have to start taking casualties from the second day. They would be allocated to regions by turn, and some regions might receive more than one flight load of casualties in a day. After five days the more seriously injured patients who had been held in the Gulf would begin to arrive. The Ministry of Defence currently does not envisage that fighting will last for more than five days. The load on the NHS might, however, be heavier than the Ministry of Defence is currently predicting, and William Waldegrave, Secretary of State for Health, has said that he will ask the Treasury for more money if necessary.

What should the doctors, nurses, and managers who have been charged with the local organisation of the NHS response do? What effect will our actions have on the normal work of the health service, and will we be able to cope? If diplomacy prevails will our efforts have been wasted or are there lessons for peacetime emergency medicine?

Much has been learnt already from civilian major incidents. Communications and the command structure and coordination across professional and geographical boundaries are recognised as essential components of an efficient plan. The response to last week's train crash at Cannon Street station in London clearly showed the value of a well rehearsed major accident procedure.

In contrast, our experience of war surgery is limited. Whereas most of the commuters into Cannon Street had sustained minor trauma, we can expect many more major injuries from armed conflict. Military surgeons plan to resuscitate and stabilise those with major trunk injuries and to decontaminate any victims of chemical weapons in the war theatre. The on site triage and staged evacuation through military facilities should prevent a rapid accumulation of critically injured patients in the NHS, but there could be a heavy load of postoperative complications, including renal problems.

Limb injuries and burns will present a bigger problem to the NHS. Initial surgery in the Gulf will be limited to extensive debridement. It may not be possible to apply external fixators to compound fractures with great precision. Temporary shunts may be used for vascular injuries. Those with burns over $15-40 \%$ of their body surface area will be flown back to the United Kingdom; some can be expected to have respiratory difficulties. Psychiatric problems may occur in all these patients as well as in the uninjured.

The problem for the NHS is therefore different from that encountered in a civilian incident. There will be little need for heroic lifesaving operations. The major burden will be time consuming reconstructive surgery, intensive care, high dependency nursing, and psychiatric treatment.

Plans for the reception of these casualties are well developed. Regional control centres will be responsible for transport to designated hospitals after triage at the local airport. Some hospitals can expect to receive many patients; others may have a support role. All can expect to be involved.

A comprehensive communication network has already been established. Those specialties most likely to be directly involved have been asked to identify their operative and staff requirements. Clearly, plans must be flexible, but this should not be an excuse for lethargy. Policies for bed evacuation, equipment supply, and staff call out must be established and held in readiness.

These preparations should not disrupt normal NHS work. If war is declared elective work will be curtailed and there may be some temporary redistribution of civilian emergencies, but the overall effect on the running of the health service should be minimal. The readiness of military hospitals to take back casualties as quickly as possible will encourage a rapid return to normal in the NHS.

Whatever the outcome of continued international negotiations, these preparations will have increased our understanding of the central issues in major incident planning and the problems inherent in the multidisciplinary response required to treat seriously injured patients. Let us hope that diplomacy does prevail and that these are the only benefits.

DAVID W YATES

Professor of Accident and Emergency Medicine,

University of Manchester

Hope Hospital,

Salford M6 8HD 